\title{
HIGH INJECTION PRESSURE IMPACT ON A DIRECT INJECTION DIESEL ENGINE
}

\author{
Srinath Pai1, Abdul Sharief', Shiva Kumar', Sreeprakash B1 \\ ${ }^{1}$ Dept of Mech. Engg., Srinivas School of Engineering, Mangalore-575021, Karnataka, India \\ 2P.A.College of Engineering, Mangalore-574153, Karnataka, India \\ ${ }^{3}$ Dept of Mech. Engg., MIT, Manipal-576104, Karnataka, India \\ Email: srinath_pai@rediffmail.com
}

\begin{abstract}
Diesel engines are the primary source of power for heavy duty vehicles; diesel engines have better fuel economy than equivalent gasoline engines and produce less green house gas emission. On the other hand, formation of smoke due to diffusion combustion and emission of oxides of nitrogen released due to high combustion temperatures are the major limitations of the existing diesel engine designs. Diesel engine manufacturers have to address these most critical situations to meet the future emissions regulations whilst improving performance and fuel economy at a minimal cost. The fuel economy, increased dynamic response and strict exhaust emission regulations resulted in invention of new technology development required improving the diesel engine performance along with exhaust emissions reduction. These improvements are made possible with new fueling technologies by improvements in combustion process through increased injection pressure. High pressure fuel injection results in better fuel atomisation and improves the fuel/air mixing to promote complete combustion, thereby increasing the fuel efficiency with emission control. The objective of this paper is to investigate the effect of fuel injection pressure on performance, fuel consumption and emission of a diesel engine. A study was done on a single cylinder 4 stroke direct injection diesel engine and the performance and emission characteristics were presented graphically. Based on experimental results, the best performance was found at 220 bar fuel injection pressure.
\end{abstract}

Key words: Diesel engine, Combustion process, Fuel injection pressure, Particulate matter, Nitrogen Oxide (NOx).

\section{I.INTRODUCTION}

Diesel engines due to their higher efficiency compared to spark ignition engines, have found increased uses in wide ranging applications, such as power stations and as prime movers with heavy duty and light duty applications. Diesel engine manufacturers over the past three decades are struggling to address the harmful effects of exhaust gas emissions to meet current and future government regulations, which limit particulate and Nitrogen Oxide (NOx) emissions.

A number of technologies have been implemented to achieve both better efficiency and lower emissions. Particulate Matter (PM) and NOx production along with engine noise is highly dependent on the combustion process. Complete combustion minimises the emissions. The load generated by a diesel engine is controlled by the quantity of fuel injected. Hence complete control over fuel injection is absolutely needed for the best performance of a diesel engine. Precise control over the fuel injection, spray atomisation and fuel-air mixing is essential in making improvements to the combustion process. High pressure injection is used to produce very fine atomisation of fuel which reduces the delay period, combustion duration, and also reduction in smoke formation and NOx emission.

High pressure injection of fuel is an excellent method used to promote the atomisation of fuel. Atomisation by high pressure injection can reduce both particulate and fuel consumption, and can increase engine power $[1,6]$. When fuel injection pressure is low, fuel particle diameters will enlarge and ignition delay period during the combustion process will increase [2,3]. Engine performance decreases because of poor combustion. When injection pressure is increased, fuel particle diameters become smaller. Since mixing of fuel to air becomes better during ignition period, engine performance will increase. If injection pressure is too high, ignition delay period becomes shorter, hence possibilities of homogeneous mixing decrease and combustion efficiency decreases [2].

Direct Injection (DI) diesel engines generally offer an improvement in efficiency $[6,10]$ over indirect injection 
(IDI) systems. Direct injection system of diesel engine (DI) provides low fuel consumption compared with divided-chamber combustion system (in other words indirect injection system) (IDI), because of undivided combustion chamber and no loss at the throat. Hence, DI system is the main stream for automobile diesel engine. On the other hand, DI system is subjected to severe trade-off between NOx and PM in exhaust emission and additionally creates more white or blue smoke compared with IDI system, which requires reduction of these harmful substances from the viewpoint of global environmental protection.

In order to increase engine efficiency and reduce emissions, great attention has been focused on improving fuel atomisation. Raising fuel injection pressure has been found to be effective in promoting fuel/air mixing $[1,5]$. The mixture formation of fuel spray and air is a governing process of combustion in the DI diesel engine, which affects the subsequent ignition characteristics, combustion rate, and exhaust emissions. Therefore, precise control over the fuel injection and thus the spray formation is essential in controlling the combustion process $[2,4,5]$.

The fuel injection system in a DI diesel engine is to achieve a high degree of atomisation $[3,14]$ in order to enable sufficient evaporation in a very short time and to achieve sufficient spray penetration in order to utilize the full air charge. The fuel injection system must be able to meter the desired amount of fuel, depending on engine speed and load, and to inject that fuel at the correct time with the desired rate. Further, depending on the particular combustion chamber, the appropriate spray shape and structure must be formed.

In general, higher injection pressures significantly reduce particulate matter emissions $[1,6,13,16]$; this is often attributed to improved atomisation and enhanced air entrainment, resulting in a leaner mixture in the spray core and hence lower soot formation. Conversely, incylinder studies suggest that soot formation is actually enhanced by more rapid evaporation of the fuel, but improved mixture also increases soot oxidation rates, resulting in a net reduction in engine-out soot. Higher injection pressures reduce the size of the emitted particles, with significant reductions in the number of accumulation-mode particles. The primary effect of increasing the injection pressure on the diesel ignition process is to reduce the physical delay, i.e., the time required for the droplets to evaporate and mix with air to form a combustible stoichiometry. Chemical effects, relating to the break-up of long chain hydrocarbons and the formation of radicals in the precombustion reactions, are not affected by injection pressure [6].

High-pressure fuel injection can increase turbulence and mixing in the cylinder. High-pressure fuel injection changes the fuel jet shape, momentum and velocity, which in turn affects the rate of entrainment of air by the fuel and penetration of the fuel $[2,7,8]$.

In recent years, there have been efforts to bring a high pressure fuel system for promotion of mixture formation to achieve better combustion $[8,17]$ conditions by the introduction of the common-rail system. In terms of improvement in the fuel characteristics, importance is placed on improving the quality of diesel fuel and a higher injection pressure $[8,15]$ leading to better mixing and air entrainment.

High-pressure injection system enables the supply of finely atomized fuel to the combustion chamber and enabled to achieve better combustion processes [8, 16]. High fuel injection pressure allows taking full advantage of the increase of fuel flow rate. Compared to high fuel injection pressure, increased nozzle hole diameter allows a limited improvement of specific power output. An increase of fuel flow rate by increasing nozzle hole diameter produces an increase of fuel/air equivalence ratio in the jet which increases soot production and thus limits the potential to increase specific power. At part load, soot emissions are increased when nozzle hole diameter is increased. Hence, the best full load/part load trade off is given by high fuel injection pressure [17].

Required characteristics of highly pressurized fuel for injection:

1. Injected fuel must have sufficient pressure to penetrate the dense combustion chamber air mass. Air at high pressure in the chamber with the density of the air charge makes it even more difficult to distribute fuel through the tightly packed air molecules.

2. At high rotational speeds, the amount of time available for the injection of fuel is very less. Injected 
fuel must be atomized, distributed, mixed with air, absorb heat, converted into vapour and begin burning near the end of the compression stroke, just before TDC. Since fuel is injected only near the end of compression stroke, these events must be accomplished quickly to allow for adequate combustion time during power stroke. High pressure injection helps to facilitate a rapid execution of the combustion sequence. This is especially important as engine speed increases. Time available for injection diminishes as the engine speed increases and hence corresponding increased injection pressures are required to quickly deliver fuel into the combustion chamber.

3. High pressure is necessary to break-up the liquid fuel into a fine mist. This process called atomisation is enhanced with high injection pressures. Higher pressurization produces increasingly smaller droplets of fuel which readily absorb heat and burn.

When highly pressurized, fuel will break up into increasingly smaller droplets promoting better fuel economy, enhanced performance and lower emissions.

The fuel injection pressure in a standard diesel engine is in the range of 200 to $1700 \mathrm{~atm}$ depending on the engine size and type of combustion system employed [Heywood,1988].

\section{EXPRIMENTAL SET UP AND}

\section{A. TEST PROCEDURE}

Experiments were conducted on a Kirloskar make DA10 model single cylinder four stroke, air cooled $7.4 \mathrm{~kW}$ (10 hp) capacity diesel engine coupled to an electric current dynamometer for loading purpose. Technical specifications of the engine are as given in Table 1 . Engine is set up as shown in Fig. 1.

Thermocouples are provided at appropriate positions while engine is run with a rated speed of $1500 \mathrm{rpm}$ and injection pressure 180 bar. Experiments were repeated with the rated speed and injection pressure is varied to 190 bar, 200 bar, 210 bar and 220bar. During these trials, injection pressure of the injector can be varied by adjusting the fuel injector spring tension.
Table 1. The engine specification details

\begin{tabular}{|l|l|}
\hline Engine make & Kirloskar DA10 \\
\hline Engine power & $7.4 \mathrm{~kW}$ ( 10 hp) \\
\hline $\begin{array}{l}\text { Number of cylinder/ } \\
\text { strokes }\end{array}$ & $\begin{array}{l}\text { Single cylinder, } 4 \\
\text { stroke }\end{array}$ \\
\hline Method of cooling & Air cooled with axial fan \\
\hline Bore X Stroke & $87.5 \mathrm{~mm}$ X 110mm \\
\hline Rated speed & $1500 \mathrm{rpm}$ \\
\hline Compression ratio & $17.5: 1$ \\
\hline Fuel injection type & Direct Injection \\
\hline Injection timing & 23 degree btdc \\
\hline $\begin{array}{l}\text { Rated Injection } \\
\text { Pressure }\end{array}$ & 180 bar \\
\hline Temperature sensor & $\begin{array}{l}\text { Type: RTD, PT100 and } \\
\text { Thermocouple, Type K }\end{array}$ \\
\hline Loading system & $\begin{array}{l}\text { Electrical Lamp Load, } \\
5 \mathrm{~kW}\end{array}$ \\
\hline
\end{tabular}

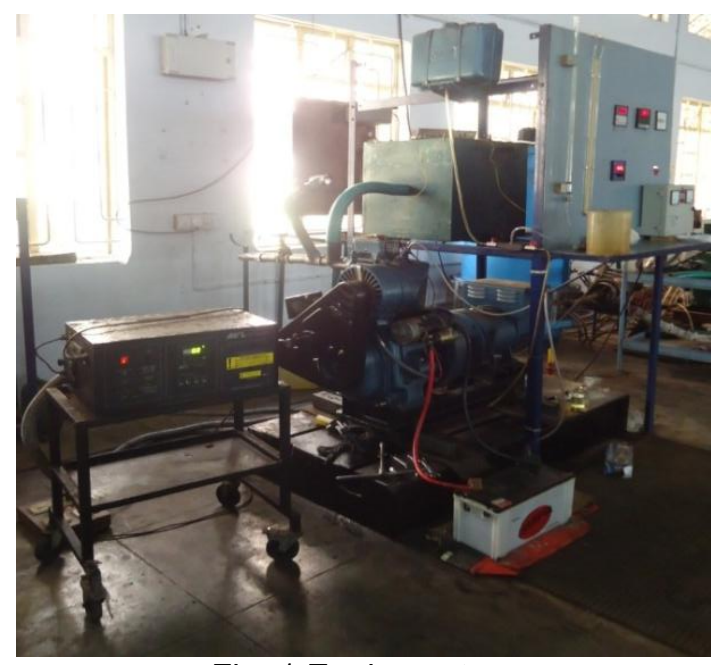

Fig. 1.Engine set up

Table 2. Exhaust Analyzer Specification Details

\begin{tabular}{|l|l|l|}
\hline $\begin{array}{l}\text { Measurabl } \\
\text { e values }\end{array}$ & $\begin{array}{l}\text { Measurement } \\
\text { range }\end{array}$ & Resolution \\
\hline $\mathrm{CO}$ & $0 \ldots 10 \%$ Vol. & $0.01 \%$ Vol. \\
\hline $\mathrm{HC}$ & $0 \ldots 20,000 \mathrm{ppm}$ & $10 \mathrm{ppm}$ \\
\hline $\mathrm{CO}_{2}$ & $0 \ldots 20 \%$ Vol. & $0.1 \%$ Vol. \\
\hline $\mathrm{O}_{2}$ & $0 \ldots 22 \%$ Vol. & $0.01 \%$ Vol. \\
\hline $\mathrm{NO}$ & $0 \ldots 5,000 \mathrm{ppm}$ & $1 \mathrm{ppm}$ \\
\hline Lambda & $\begin{array}{l}0 \ldots 9.999 \\
\text { calculated }\end{array}$ & 0.001 \\
\hline
\end{tabular}




\section{RESULT AND DISCUSSION}

The results obtained from the experiments are represented in form of charts and are discussed as follows

\section{A.Performance Parameters}

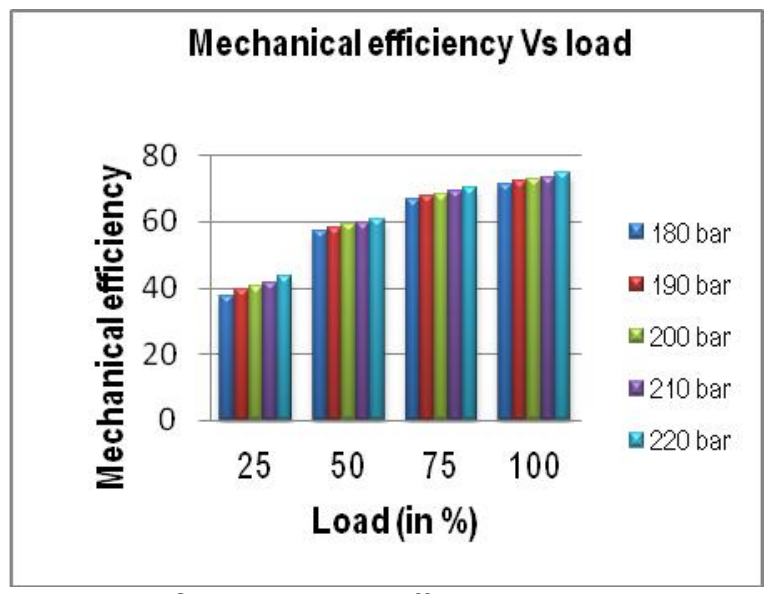

Fig. 2 .Mechanical efficiency Vs load.

From fig. 2, it is observed that for the fixed engine speed with variations on engine loads and increasing injection pressure, the mechanical efficiency starts increasing. It leads to improvement in engine performance.

When injection pressure is increased, the fuel particle diameters will become small. Since formation of mixing of fuel to air becomes better during ignition period, engine performance will increase. It is observed that the mechanical efficiency is improved with injection pressure and is found to be the best at injection pressure $220 \mathrm{bar}$ due to better combustion.

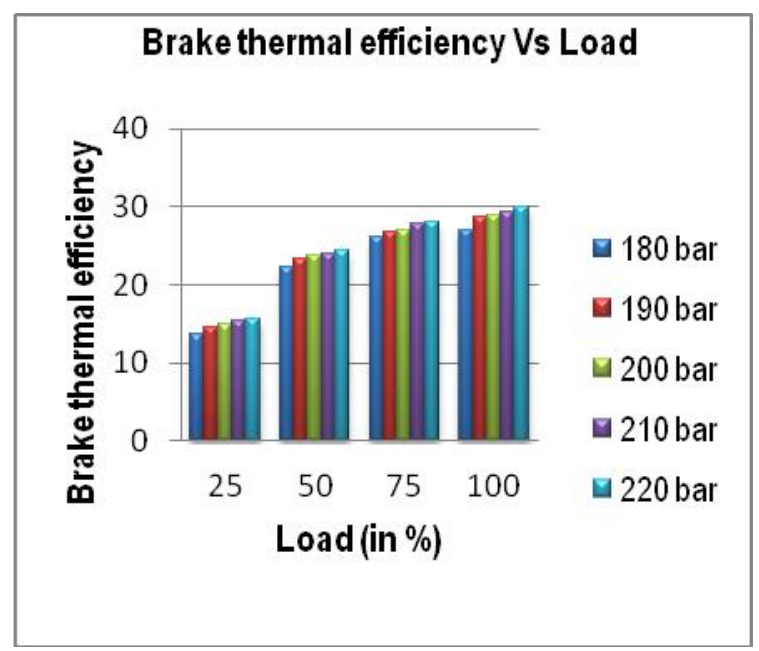

Fig. 3. Brake thermal efficiency Vs load.
Fig. 3 shows the variation of Brake Thermal Efficiency (BTE) with increasing injection pressure for different loads. It is observed that at each load, BTE increases considerably from 180 to 220 bar for the entire load range and is found optimum at injection pressure 220 bar. This may be attributed to the better fuel and air mixing and better atomisation as a result of increased injection pressure. This leads to improved combustion process and hence improved efficiency.

The fuel injection pressure affects the Total Fuel Consumption (TFC) performance of the engine as shown in fig 4. More the load on engine, more the power required to sustain; in turn it needs more fuel consumption to produce the power essential to take the loads. Hence TFC increases with the load, whereas the impact of fuel injection pressure shows that the highest TFC takes place at 180 bar injection pressure and the least TFC at 220 bar.

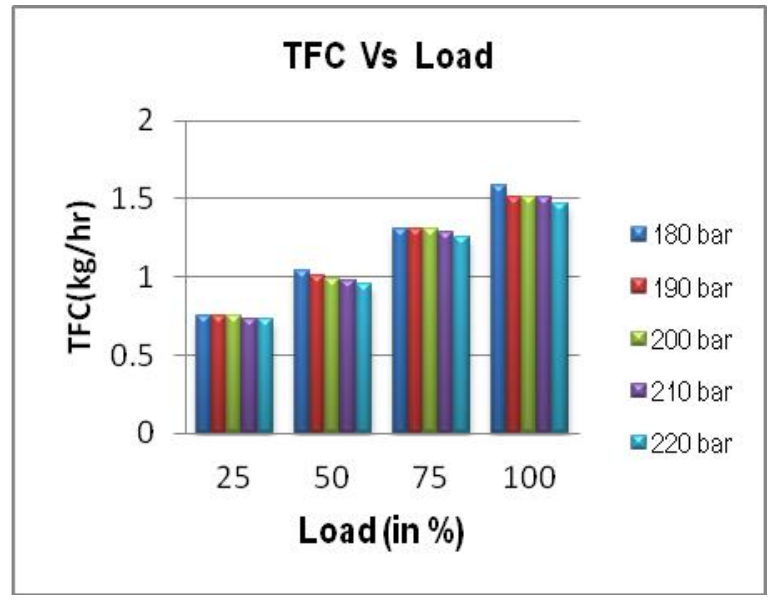

Fig. 4 .Total Fuel Consumption (TFC) Vs load.

\section{B. Emission parameters}

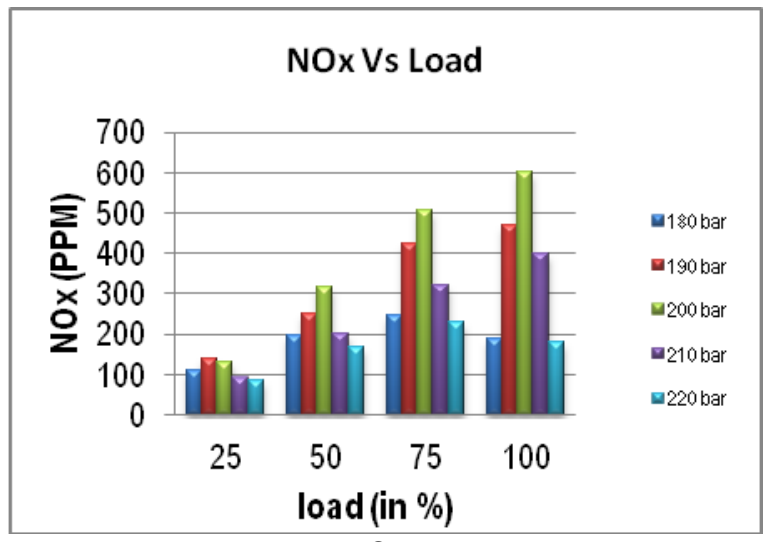

Fig. 5. $\mathrm{NO}_{\mathrm{x}}$ Vs load. 
Fig. 5 shows the variation of NOx emissions with different injection pressures for part load and full load conditions. NOx emissions are lower for 220 bar injection pressure in comparison with all injection pressures. It is also noted that, as the injection pressure increases, NOx increases for all loads till 200 bar, since the formation of $\mathrm{NO}_{x}$ is very sensitive to temperature, which is responsible for thermal $\mathrm{NO}_{\mathrm{x}}$ formation.

NOx concentration increases monotonically with increase in engine load except for the lowest load. In case of engines with less injection pressure, more fuel is injected at high engine loads, leading to improper atomisation and penetration, which results in higher temperature of the burning gas. NOx concentration is drastically reduced after 200 bar and recorded to be best at 220 bar due higher injection pressure leading to improved atomisation and penetration resulting in better combustion. When high pressurised fuel is injected into the engine cylinder, the injected fuel particles get smaller depending on the increasing injection pressure, and NOx formation is lowered by reducing the ignition delay.

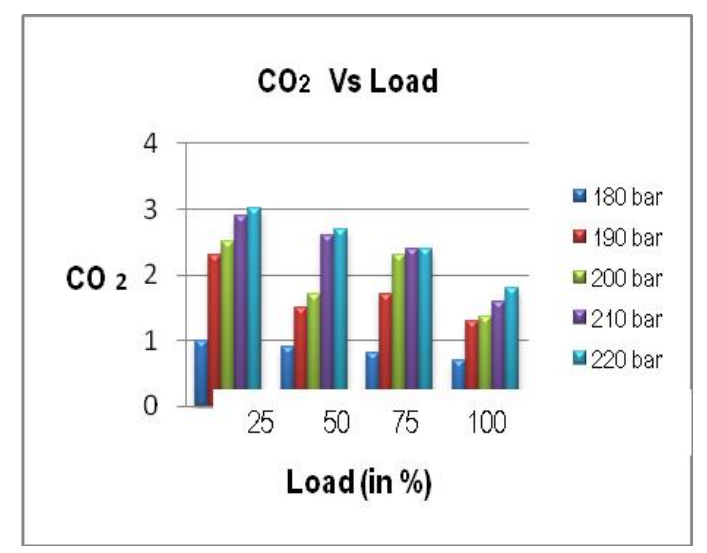

Fig. 6. $\mathrm{CO}_{2}$ Vs load.

From fig. 6 , it is observed that $\mathrm{CO}_{2}$ emission increases with the increase of injection pressure. It was found maximum at 220 bar injection pressure for all the loads. This is because increase of injection pressure tends to finer fuel spray mixes fuel and air thoroughly makes the combustion process complete. At low injection pressure, fuel droplet diameter gets enlarged resulting in longer ignition delay leading to incomplete combustion and hence least $\mathrm{CO}_{2}$ emission was observed at lowest injection pressure of 180 bar injection pressure. It is also observed that $\mathrm{CO}_{2}$ decreases with load. Generally, for a diesel engine, air to fuel ratio is high in the low and medium load regions compared to full load. Due to this, complete combustion may take place at part loads, results in high $\mathrm{CO}_{2}$ emission.

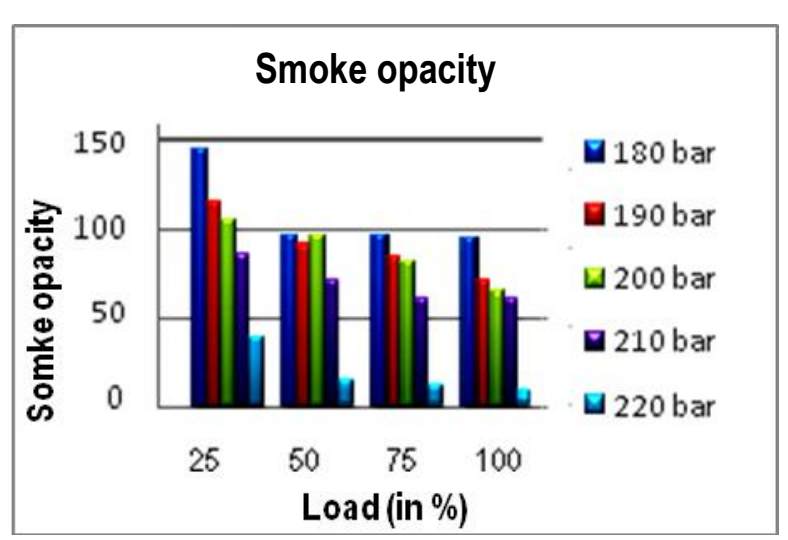

Fig. 7. Opacity Vs load.

From fig. 7, it is observed that, as the injection pressure increases, smoke opacity gets reduced with increase in injection pressure for all loads. This is probably because of the smaller drop size of the injected fuel results in better atomisation of fuel and sprays propagation leading to improved and complete combustion.

\section{CONCLUSION}

The conclusions derived from present experimental investigation to evaluate performance and emission characteristics on a single cylinder four stroke light duty diesel engine at different injection pressures are summarized as follows:

- As per the results, BTE was found to increase with increasing pressure and was highest at 220 bar pressure whereas TFC was found to be least at same pressure.

- Nitrogen oxide emission was found decreased with higher injection pressure and lowest at 220 bar pressure, where as $\mathrm{CO}_{2}$ (the most important product of combustion is a greenhouse gas in that it causes atmospheric temperature to rise) was found least at 220 bar injection pressure and $\mathrm{CO}_{2}$ increased in the order of 180-190-200-210220 bar fuel injection pressure.

- It can be seen from the results that smoke formation is more sensitive to the lower injection pressure and reduced with injection 
pressure increase for all loads as a result of better combustion.

- It is found that 220 bar injection pressure was found to be the best among all the trials at various load conditions.

- Finally, it is concluded that the information obtained from this investigation is useful in the analysis of injection pressure impact in increasing the performance of diesel engines along with their emission control to meet current and future government regulations.

\section{ACKNOWLEDGEMENT}

The author is thankful to the Staff and Management of Srinivas School of Engineering, Mukka, and P.A College of Engineering, Mangalore, for their support and encouragement.

\section{REFERENCE}

[1] Dae Yong Jeong, Sung Jin Park and, Jong Tai Lee, 'An Analysis on the Suitable Injection Pressure of Diesel Injection with High Pressure',

[www.ilasseurope.org/ICLASS/iclass2003/fullpapers/1429.pdf]

[2] K. Kannan and M. Udayakumar 'Experimenal study of the effect of fuel injection pressure on diesel engine performance and emission' ARPN Journal of Engineering and Applied Sciences VOL. 5, NO. 5, MAY 2010 - ISSN 1819-6608.

[3] Rosli Abu Bakar, Semin and Abdul Rahim Ismail, 'Fuel Injection Pressure Effect on Performance of Direct Injection Diesel Engines Based on Experiment' American Journal of Applied Sciences 5 (3): 197-202, 2008 ISSN 1546-9239 Science Publications

[4] T. C. Wang, J. S. Han, X. B. Xie, M. C. Lai1 and N. A. Henein, 'Parametric Characterization of High-Pressure Diesel Fuel Injection Systems' 412 / Vol. 125, APRIL 2003, Transactions of the ASME.

[5] B. Mahr, 'Future and Potential of Diesel Injection Systems' THIESEL 2002 Conference on Thermo- and Fluidynamic Processes in DieselEngines,

[www.sciencedirect.com/science/article/pii/S092058610700755 9]

[6] Essam M. EL-Hannouny and Patrick V. Farrell, 'Effect of Injection Parameters and Injection System on Spray Characteristics for HSDI Diesel Engines' 9th International Conference on Liquid Atomisation and Spray Systems Sorrento, 13-18July ICLASS 2003,

[ www.ilasseurope.org/ICLASS/iclass2003/fullpapers/1403.pdf]
[7] G. P. McTaggart-Cowan, S. N. Rogak, W. K. Bushe, P. G. Hill and S. R. Munshi, 'The Effects of High-Pressure Injection on a Compression-Ignition, Direct Injection of Natural Gas Engine, Journal of Engineering for Gas Turbines and Power APRIL 2007, Vol. 129 / 579.

[8] Seang-Wock Lee, Simsoo Park and Yasuhiro Daisho, 'An experimental study of the effects of combustion systems and fuel properties on the performance of a diesel engine' Proceedings of the Institution of Mechanical Engineers, Part D: Journal of Automobile Engineering 2004 218: 1317

[9] Rich Schoonover, 'The First Field Application of High-Pressure Fuel Injection on a Two-Stroke Cycle, Large Bore Reciprocating Engine' 1999 Gas Machinery Conference Enginuity, LLC 09/28/99

[10] J G Suryawanshi and N V Deshpande, 'Performance, Emission and Injection Characteristics of a $\mathrm{Cl}$ Engine Fuelled with Honge Methyl Ester' Indian Journal of Science and Technology Vol.2 No.10 (Oct 2009) ISSN: 0974.

[11] I. Pielecha, K. Wislocki, J. Czajka and D. Maslennikov, 'The Qualitative Spray Characteristics of High-Pressure Gasoline Injection System' ILASS - Europe 2010, 23rd Annual Conference on Liquid Atomisation and Spray Systems, Brno, Czech Republic, September 2010,

[www.ilasseurope2010.org/proceedings/files/full_papers/174.p df]

[12] Ernst Winklhofer, Erich Kelz, Alexander Morozov, 'Basic flow processes in high pressure fuel injection equipment' [www.ilasseurope.org/lCLASS/iclass2003/fullpapers/1409.pdf]

[13] X-G Wang, B Zheng, Z-H Huang, N Zhang, Y-J Zhang, and E$\mathrm{J} \mathrm{Hu}$, 'Performance and emissions of a turbocharged, highpressure common rail diesel engine operating on biodiesel/diesel blends' Proc. IMechE Vol. 225 Part D: J. Automobile Engineering Page No127-139.

[14] O. Bunes, and P.M. Einang, 'Comparing the performance of the common rail fuel injection system with the traditional injection system using computer aided modelling and simulation' MARINTEK paper at ENSUS 2000, International Conference on Marine Science and Technology for Environmental Sustainability, Newcastle, September 2000.

[15] Keshav S. Varde and Takashi Watanabe, 'Characteristics of High Pressure Spray and Exhaust Emissions in a Single Cylinder DI Diesel Engine' Seoul 2000 FISITA World Automotive Congress June 12-15,2000, Seoul, Korea.

[16] KoreaYasuo Takagi, 'A new era in Spark Ignition engines featuring high pressure direct injection' Twenty-Seventh Symposium (International) on Combustion/The Combustion Institute, 1998/pp. 2055-2068.

[17] Maria Thirouard, Sylvain Mendez, Pierre Pacaud, Vincent Chmielarczyk and Didier Ambrazas, 'Potential to Improve Specific Power Using Very High Injection Pressure In HSDI Diesel Engines' SAE Paper 01-1524, 2009. 